The book is divided into twelve sections, these begin devoted to the alimentary system, the circulatory system, the blood, the ductless glands, the respiratory system, the urinary system, the skin, the nervous system, metabolism, intoxications and poisons, the infective diseases of temperate climates, tropical diseases, and finally there is a chapter on the inter-relation of organs in disease.

It is impossible to attempt a complete review of a text-book of medicine. Turning to subjects which will be of special interest to practitioners in India, we may begin with chronic pulmonary tuberculosis. It is admirably treated. Its mode of inception, and the fallacies attending on the physical signs are so stated as to give an excellent diagnostic picture. Typhoid fever, too, is dealt with in a masterly manner, and the article is crammed with information. It is needless to refer to other diseases; we have found their descriptions to be of uniform excellence. We have only one adverse criticism to make, and that is with reference to rheumatic fever. Of this Dr. Dixon Mann writes that "there can be little doubt that acute rheumatism is due to the invasion of micro-organisms, although so far none of a causal nature have been detected." We do not thiık that sufficient weight has been given to the work of Poynton and Payne in this counection. The book has been written by the collaboration of sixteen medical men of standing, contaius 75 illustrations and diagrams, and is printed on thin glazed paper, so that its entire thickness, including its thin boards, is only an inch and-a-half. We were disposed to think that the binding was not sufficiently substantial, but are of opinion, after a considerable use of the book, that we were mistaken, and that the publishers have given as much forethought to this as has evidently been given to the preparation of the substance of the book. We congratulate the editor, contributors, and publishers on this addition to medical literature.

Obstetric and Gynæcologic Nursing.-By Edward P. Davis, A.M., M.D., Professor of Obstetrics in the Jefferson Medical College and in the Philadelphia Polyclinic. $12 \mathrm{mo}$ volume of 402 pages, fully illustrated. Second Edition, thoroughly revised. Philadelphia, New York, London : W. B. Saunders \& Co, 1904. Polished Buckram, $\$ 1.75$ net.

THis book was originally prepared for the Training Schools for Nurses of the Jefferson and Philadelphia Hospitals. It is divided into two parts, the first dealing with obstetric nursing, includes a clear and concise account of the anatomy and physiology of pregnancy, which is followed by chapters on the nursing of pregnancy, and its complications, a description of labour and its management, the accidents of pregnancy and labour, obstetric surgery, the management of the new-born infant, \&c. The second part dealing with gynæcological nursing contains very full and clear directions as to the preparation of a patient for examination, douching, gynæcological operations, including abdominal sections, with the after-care of the patient. This is followed by an appendix on dietary, giving directions for the preparation of such articles as albumen water, broths, beef tea, \&c., succeeding which there is a short account of the preparation of surgical supplies, including the sterilization of instruments, dressings, silks, sponges, \&c.

The book is theroughly practical and up-todate, and we are unable to find any important omissions. The author has, we think, succeeded admirably well in giving just the necessary information that it is essential for a nurse to know in order that she may take an intelligent interest in her work.

Greatstress has been laid, and very rightly too, on the extreme importance of rigid antisepsis, and though perhaps it might be said that the precautions recommended to attain this object, are, in some cases, over-elaborate, yet this is undoubtedly a fault on the right side.

We most strongly recommend the work to those for whom it is written, and at the same time there is much information in it which the practitioner will find of great help and use. The printing, illustrations and general "get-up" of the book leave little to be desired, and are in keeping with the high standard that is associated with this firm of publishers.

\section{A Text-Book of Diseases of Women.-By} Charles B. Penrose, M.D., Ph.D., formerly Professor of Gynæcology in the University of Pennsylvania. Fifth Edition, thoroughly revised. Octavo volume of 539 pages, with 221 fine original Illustrations. Philadelphia, New York, London: W. B. Saunders \& Co., 1904. Cloth, $\$ 5 \cdot 75$ net.

THovgh this book made its first appearance only as recently as 1897 , it has already reached the fifth edition. This fact sufficiently vouches for its merits and popularity. The present edition shows evidence of careful revision, and a number of new illustrations, as well as a considerable amount of fresh matter, have been introduced. The work gives a very full and lucid account of the diseases of women, the description of the various operations being especially clear and complete. It is thoroughly reliable and up-to-date, is written in a very readable form, and is profusely illustrated. It is a book that can be most strongly recommended both to the student and to the medical practitioner, as quite one of the-best, and most reliable text-books on modern gynæcology, and one that is likely to have a very large sale in this country as it becomes better known.

It is excellently printed in bold and clear type, and the illustrations on the whole are exceedingly good, though there are a few that appear, perhaps, a trifle crude. 